Jurnal Intelektualita: Keislaman, Sosial, dan Sains

Volume 7, Nomor 2, Desember 2018

ISSN: 2303-2952 (print)

DOI: https://doi.org/10.19109/intelektualita.v7i2.2731

\title{
Pengaruh Permainan Tradisional Engkleng terhadap Pemahaman Konsep Siswa KelaS III Mata Pelajaran Matematika di SDN Bangsa Negara Kabupaten OKU Timur
}

\author{
Dedek Yunita \\ Fakultas Ilmu Tarbiyah dan Keguruan \\ Universitas Islam Negeri Raden Fatah Palembang \\ Email: dedekyunita@gmail.com
}

\begin{abstract}
Abstrak
Pemahaman konsep siswa dapat dilihat dari rata-rata nilai mean hasil belajar siswa kelas kontrol yaitu 72,75 sedangkan nilai mean hasil belajar siswa kelas eksperimen yaitu 84,73. Kemudian hasil analisis data dengan menggunakan statistik uji " $\mathrm{t}$ " diperoleh dalam perhitungan $\left(t_{o}=3,84\right)$ dan besarnya $t$ yang tercantum pada tabel $\left(t_{t . t s .5 \%}=2,02\right)$ dan $\left(t_{\text {t.ts. } 1 \%}\right.$ $=2,71)$ maka dapat diketahui bahwa $t_{0}$ lebih besar $t_{t}$; yaitu 2,02<3, 84>2,71. Karena $t_{0}$ lebih besar dari $t_{t}$ maka hipotesa nihil yang diajukan ditolak, ini berarti bahwa adanya pengaruh permainan tradisional engklengterhadap pemahaman konsep siswa Kelas IIIpada mata pelajaran matematika di SDN Bangsa Negara OKU Timur.
\end{abstract}

Kata Kunci: Permainan Engkleng, Pemahaman Konsep, Matematika

Indonesia merupakan negara yang memiliki beragam kebudayaan. Jika kita membahas mengenai permainan tradisional maka hampir disetiap daerah di Indonesia memiliki permainan tradisional, baik yang memang berbeda jenis dan teknis permainannyaataupun permainan yang teknis bermainnya sama hanya saja penyebutan istilah yang berbeda di suatu daerah. Salah satu contohnya adalah permainan engkleng, dimana permainan ini adalah permainan tradisional yang dilakukan dengan cara melompat dengan satu kakipada bidang datar yang telah diberi garis pola kotak-kotak. Dimana alat yang digunakan dalam permainan ini sangat sederhana, hanya pecahan genting yang disebut gacuk, dan pola permainan engkleng yang terdiri dari beberapa bangun datar. Permainan ini biasanya dimainkan oleh dua orang atau lebih.

Permainan yang serupa dapat ditemukan dibeberapa daerah dengan sebutan yang berbeda: (1) Engkleng sebutan permainan dari daerah Jawa, khususnya dari daerah Pacitan Provinsi Jawa Timur [1]. (2) Provinsi Bangka bernama Cak Ingkling [1]. (3) Provinsi Jawa Barat bernama Tepok Gunung [1] (4) Provinsi Lampung bernama Taplak [2]. (5) Provinsi Riau bernama Kelas, (6) Provinsi Nusa Tenggara Barat bernama Ceprak.

Mengingat Indonesia memiliki berbagai macam permainan tradisional yang ternyata memiliki nilai edukasi yang baik, maka untuk melestarikan budaya agar tetap ada di tengah-tengah masyarakat khususnya dikalangan anak-anak hendaknya dikenalkan serta diajarkan permainan tradisonal yang memiliki nilai edukasi tersebut pada proses pembelajaran di sekolah tentunya disesuaikan dengan materi yang akan diajarkan, karena dengan mengajak anak bermain mengenai materi ajar, diharapkan dapat menciptakan pembelajaran yang menyenangkan sehingga membantu anak-anak memahami materi yang disampaikan guru.

Tersedia Online di http://jurnal.radenfatah.ac.id/index.php/intelektualita 
Dedek Yunita

Pengaruh Permainan Tradisional Engkleng terhadap Pemahaman Konsep Siswa

KelaS III Mata Pelajaran Matematika di SDN Bangsa Negara Kabupaten OKU Timur

Berbicara mengenai permainan tentu erat sekali dengan anak-anak, karenadunia anak adalah dunia bermain. Sebagian besar proses belajar anak dilakukan melalui permainan yang mereka lakukan [3]. Pada penelitian Piaget dan Vygosky, peneliti pada dunia anak menemukan jika bermain merupakan salah satu komponen terpenting dalam kesuksesan anak disekolah. Melalui bermain anak belajar mengemukakan pendapat, mengolah peraturan, memperoleh pengetahuan, dan memperluas keahlian berpikir kognitif mereka [4].

Disini tentunya pemilihan jenis permainan yang sesuai dengan perkembangan anak perlu dilakukan agar pesan edukatif dalam setiap permainan dapat ditangkap anak dengan mudah dan menyenangkan [3]. Kondisi pembelajaran yang menyenangkan sekaligus menantang inilah yang mempunyai potensi besar dalam membentuk karakter anak [3]. Karena ada beberapa permainan anak yang dapat membantu pemahaman konsep anak terhadap suatu pelajaran di sekolah. Sebagaimana yang di kemukakan Dienes dalam Tembokan bahwasannya "tiap konsep atau prinsip matematika yang diajarkan dalam bentuk konkret akan lebih dipahami anak, proses belajar dapat di tingkatkan dengan bermain" [5].

Permainan berasal dari kata dasar main yang memiliki arti berbuat untuk menyenangkan hati atau melakukan perbuatan untuk menyenangkan hati. Dalam makna ini permainan yang merupakan tindakan bermain memberikan penekanan pada perbuatan yang menyenangkan yang merupakan karakteristik khas tindakan bermain ini [6]. Permainan merupakan suatu aktivitas bermain yang di dalamnya telah memiliki aturan yang jelas dan disepakati [7]. Santrock menyatakan bahwa permainan (Play) ialah suatu kegiatan menyenangkan yang dilakasanakan untuk kepentingan kegiatan itu sendiri. Permainan merupakan aktivitas bermain yang didalamnya telah memiliki aturan yang jelas dan disepakati bersama [7].

Menurut Nor Izatil Hasanah dan Hardiyanti Pratiwi permainan tradisional merupakan permainan yang diturunkan dari generasi ke generasi berikutnya melalui lisan. Permainan ini biasanya hanya menggunakan aturan sederhana yang disepakati secara bersama-sama dengan menggunakan alat-alat sederhana yang biasanya merupakan benda-benda disekitar anak seperti permainan dakon, tali, logo dan engklek [8].

Permainan engkleng adalah permainan tradisional yang dilakukan dengan cara melompat-lompat pada bidang datar, lalu di buat kotak-kotak kemudian melompat dengan satu kaki ke kotak berikutnya.Menurut Rahmawati dalam Anisa menyatakan bahwa permainan tradisional engkleng adalah permainan yang melompati satu garis dengan satu kaki [9]. 


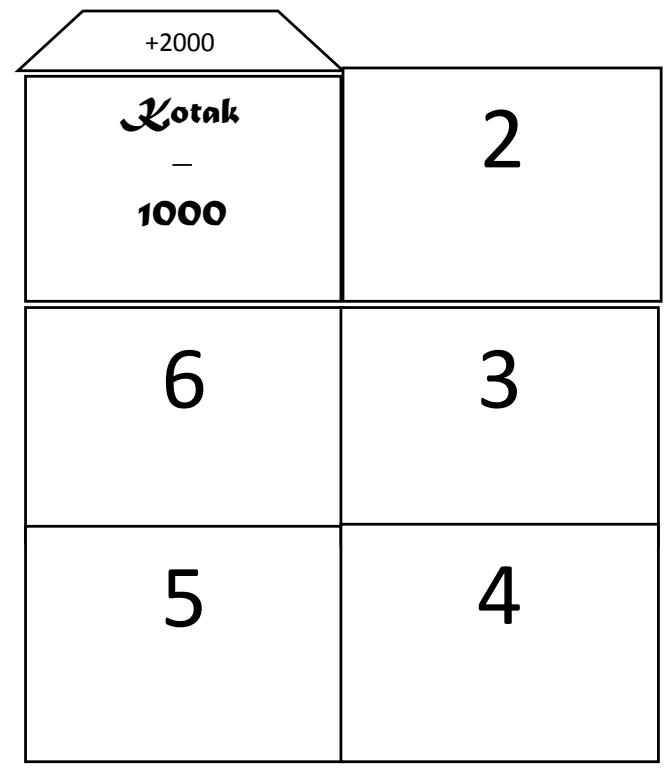

Pada gambar diatas merupakan jenis engkleng seribu, didalam penelitian ini permainan engkleng seribu sebagai media yang dijadikan sebagai alat untuk mendapatkan angka yang nantinya akan dijumlahkan atau dikurangkan oleh siswa. Cara bermain permainan ini adalah:

1. Permainan ini minimal terdiri dari dua orang, jika pemainnya banyak biasanya permainan ini dilakukan secara berkelompok yaitu terdiri dari dua kelompok.

2. Pada permainan ini tiap pemain memerlukan gacuk yang terbuat dari pacahan genting dengan bentu persegi ukuran sekitar $3 X 3 \mathrm{~cm}$, oleh karena itu setiap siswa harus memiliki gacuk.

3. Untuk menentukan siapa yang bermain terlebih, tiap pemain/kelompok hompimpa, kemudian pemain yang menang meletakkan gucuk di kotak pertamakemudian bermain dengan cara mendorong gacuk tersebut dengan ujung kaki dari satu kotak ke kotak berikutnya sesuai pola permainan engkleng seribudengan satu kaki diangkat.

4. Setelah sampai ke kotak nomor 5 siswa boleh meletakkan kedua kakinya. Selanjutnya gacuk diambil menggunakan tangan dan di letakkan ke kotak nomor 6, di kotak inilah siswa harus memperkirakan agar nantinya gacuk yang didorong menggunakan kaki dapat tepat sasaran ke poin nilai yang ada di kotak nomor 8 (syarat siswa mendapat poin yaitu jika gucuk tepat pada salah satu kotak poin nilai/gucuk tidak keluar garis/ tidak menempel garis).

5. Jika gacuk berada di kotak angka 5000, berarti poin nilai yang didapat adalah 5000 .

6. Selanjutnya pemain kembali dengan mengangkat satu kaki dari kotak ke 4,3,2,1. Setelah itu pemain bermain dengan cara yang sama seperti diatas (a-d), selama kaki pemain dan gacuk tersebut tidak menginjak/keluar garis pada pola permainan engkleng pemain akan terus bermain, dan nilai angka yang di dapat akan diakumulasikan. 
Dedek Yunita

Pengaruh Permainan Tradisional Engkleng terhadap Pemahaman Konsep Siswa

KelaS III Mata Pelajaran Matematika di SDN Bangsa Negara Kabupaten OKU Timur

Pada permainan engkleng seribu ini ternyata terdapat nilai edukasi yang dapat membantu siswa dalam memahami dan melatih kemampuan matematis siswa, karena pada permainan ini terdapat angka 1000-5000, yang bisa dijumlahkan dan bisa dikurangkan. Semakin sering anak bermain permainan ini, tentunya semakin sering berlatih dalam menjumlahkan dan mengurangkan suatu angka. Adapun dalam penelitian ini, memfokuskan pada pengaruh permainan tradisional engkleng seribu pada pemahaman matematika yang perlu diterapkan kepada anak didik di sekolah dasar sebagai pemahaman mendasar yang perlu ditanamkan sejak dini sedikitnya meliputi kemampuan: kemampuan merumuskan strategi penyelesaian, menerapkan perhitungan sederhana, mengubah suatu bentuk ke bentuk lain yang berkaitan dengan pecahan.

\section{Metode Penelitian}

Dalam penelitian ini peneliti menggunakan desain eksperimen True experimental design (eksperimen yang betul-betul), karena dalam desain ini, peneliti dapat mengontrol semua variabel luar yang mempengaruhi jalannya eksperimen. Ciri utamanya adalah sampel yang digunakan untuk eksperimen maupun sebagai kelompok kontrol diambil secara random dari populasi tertentu.Penelitian ini merupakan rancangan eksperimen ThePosttest Control group Design. Dalam rancangan ini terdapat dua kelompok yang masing-masing dipilih secara random (R). Kelompok pertama diberi perlakuan dan kelompok yang lain tidak. Kelompok yang diberi perlakuan disebut kelompok eksperimen dan kelompok yang tidak diberi perlakuan disebut kelompok kontrol. Pada kelas eksperimen, diberikan perlakuan kemudian diberikan tes. Pada kelas kontrol tidak diberikan perlakuan akan tetapi tetap diberikan tes.

\section{Hasil dan Pembahasan}

Setelah dilakuannya Posttest yaitu dalam bentuk 10 butir soal yang telah disesuaikan dengan indikator pemahaman konsep matematis untuk anak sekolah dasar pada kelas eksperimen dan kontrol maka didapatkan data nilai siswa mengenai pemahaman konsep, selanjutnya mencari perbandingan pemahaman konsep siswa kelas kontrol dan kelas eksperiman, dengan lengkah sebagai berikut:

Tabel: Perhitungan untuk Memperoleh Mean dan Standar Deviasi

\begin{tabular}{|c|c|c|c|c|c|c|}
\hline $\begin{array}{c}\mathrm{N} \\
\mathrm{o}\end{array}$ & \multicolumn{2}{|c|}{ Skor Siswa } & \multirow{\mathrm{X}}{*}{$\mathrm{X}^{\mathbf{2}}$} & $\mathrm{Y}$ & $\mathrm{Y}^{2}$ \\
\cline { 2 - 3 }$\left(\mathrm{X}-\mathrm{M}_{1}\right)$ & $\begin{array}{c}(\mathrm{Y}- \\
\left.\mathrm{M}_{2}\right)\end{array}$ & & \\
\hline 1 & 100 & 80 & 15 & 7 & 225 & 49 \\
\hline 2 & 95 & 75 & 10 & 2 & 100 & 4 \\
\hline 3 & 90 & 80 & 5 & 7 & 25 & 49 \\
\hline 4 & 75 & 70 & -10 & -3 & 100 & 9 \\
\hline 5 & 75 & 75 & -10 & 2 & 100 & 4 \\
\hline 6 & 70 & 75 & -15 & 2 & 225 & 4 \\
\hline 7 & 95 & 70 & 10 & -3 & 100 & 9 \\
\hline 8 & 85 & 75 & 0 & 2 & 0 & 4 \\
\hline
\end{tabular}


Dedek Yunita

Pengaruh Permainan Tradisional Engkleng terhadap Pemahaman Konsep Siswa

KelaS III Mata Pelajaran Matematika di SDN Bangsa Negara Kabupaten OKU Timur

\begin{tabular}{|c|c|c|c|c|c|c|}
\hline 9 & 100 & 65 & 15 & -8 & 225 & 64 \\
\hline 10 & 85 & 70 & 0 & -3 & 0 & 9 \\
\hline 11 & 70 & 85 & -15 & 12 & 225 & 144 \\
\hline 12 & 85 & 65 & 0 & -8 & 0 & 64 \\
\hline 13 & 80 & 60 & -5 & -13 & 25 & 169 \\
\hline 14 & 100 & 85 & 15 & 12 & 225 & 144 \\
\hline 15 & 80 & 60 & -5 & -13 & 25 & 169 \\
\hline 16 & 90 & 75 & 5 & 2 & 25 & 4 \\
\hline 17 & 65 & 65 & -20 & -8 & 400 & 64 \\
\hline 18 & 90 & 90 & 5 & 17 & 25 & 289 \\
\hline 19 & 80 & 60 & -5 & -13 & 25 & 169 \\
\hline 20 & & 75 & & 2 & & 4 \\
\hline & $\begin{array}{l}\Sigma \mathbf{f x} \\
=\mathbf{1 6 1 0}\end{array}$ & $\begin{array}{l}\boldsymbol{\Sigma} \mathbf{f y} \\
=\mathbf{1 4 5 5}\end{array}$ & & & $\begin{array}{l}\boldsymbol{\Sigma} \mathbf{f x}^{2} \\
=2075\end{array}$ & $\begin{array}{c}\Sigma \mathbf{f y}^{2} \\
=1425\end{array}$ \\
\hline
\end{tabular}

1. Rumus mencari mean untuk variabel 1 dengan rumus :

$$
\begin{aligned}
M_{x} \text { atau } M_{1} & =\frac{\sum x}{N_{1}} \\
& =\frac{1610}{19} \\
& =84,74 \\
& =85
\end{aligned}
$$

2. Rumus mencari mean untuk variabel 2 dengan rumus :

$$
\begin{aligned}
\mathrm{M}_{\mathrm{y}} \text { atau } \mathrm{M}_{2} & =\frac{\sum \mathrm{y}}{\mathrm{N}_{2}} \\
& =\frac{1455}{20} \\
& =72,75 \\
& =73
\end{aligned}
$$

3. Rumus mencari deviasi standar skor variabel $\mathrm{X}$ :

$$
\begin{aligned}
\mathrm{SD}_{x} \text { Atau } \mathrm{SD}_{1} & =\sqrt{\frac{\sum_{x} 2}{N_{1}}} \\
& =\sqrt{\frac{2075}{19}} \\
& =10,45 \\
& =10
\end{aligned}
$$

4. Rumus mencari deviasi standar skor variabel Y:

$$
\begin{aligned}
\mathrm{SD}_{Y} \text { Atau } \mathrm{SD}_{2} & =\sqrt{\frac{\sum_{Y} 2}{N_{1}}} \\
& =\sqrt{\frac{1425}{20}} \\
& =8,44
\end{aligned}
$$


Dedek Yunita

Pengaruh Permainan Tradisional Engkleng terhadap Pemahaman Konsep Siswa

KelaS III Mata Pelajaran Matematika di SDN Bangsa Negara Kabupaten OKU Timur

$$
=8
$$

5. Rumus mencari standard error mean variabel $\mathrm{X}$ :

$$
\begin{aligned}
\mathrm{SE}_{x} \text { Atau } \mathrm{SE}_{1} & =\frac{S D_{1}}{\sqrt{N_{1-1}}} \\
& =\frac{10,43}{\sqrt{19-1}} \\
= & \frac{10,43}{\sqrt{18}} \\
= & \frac{10,43}{4,24} \\
& =2,46
\end{aligned}
$$

6. Rumus mencari standard error mean variabel $\mathrm{Y}$ :

$$
\begin{aligned}
\mathrm{SE}_{y} \text { Atau } & \mathrm{SE}_{2}=\frac{S D_{2}}{\sqrt{N_{2-1}}} \\
= & \frac{8,44}{\sqrt{20-1}} \\
= & \frac{8,44}{\sqrt{19}} \\
= & \frac{8,44}{4,35} \\
= & 1,94
\end{aligned}
$$

7. Rumus mencari standard error perbedaan mean variabel $\mathrm{X}$ dan mean variabel $\mathrm{Y}$ :

$$
\begin{aligned}
\mathrm{S}_{M 1-M 2} & =\sqrt{\mathrm{SE}_{M 1^{2}}+\mathrm{SE}_{M 2^{2}}} \\
& =\sqrt{(2,45)^{2}+(1,94)^{2}} \\
& =\sqrt{6,0025+3,7636} \\
& =\sqrt{9,7661} \\
& =3,12
\end{aligned}
$$

Mencari $t_{\mathrm{o}}$ dengan rumus:

$$
\begin{aligned}
\mathrm{t}_{\mathrm{o}} & =\frac{\mathrm{M}_{1-} \mathrm{M}_{2}}{\mathrm{SE}_{\mathrm{M} 1-\mathrm{M} 2}} \\
& =\frac{85-73}{3,12} \\
\mathrm{t}_{\mathrm{o}} & =3,84
\end{aligned}
$$

8. Menguji kebenaran/kepalsuan

Setelah mendapatkan harga $t_{0}$ maka langkah selanjutnya adalah memberikan interpretasi terhadap $t_{0}: d f=\left(N_{1}+N_{2}\right)-2=(19+20)-2=37$. Dengan df sebesar 37 dikonsultasikan dengan tabel nilai " $\mathrm{t}$ ", baik taraf signifikan 5\% maupun taraf $1 \%$. Ternyata dengan df 37 itu diperoleh kritik " $t$ " atau tabel pada $t_{\text {tabel }}$ taraf signifikan $5 \% \mathrm{t}$ tabel atau $t_{t}=2,02$, sedangkan pada taraf signifikan $1 \%=2,71$. Karena $t_{\mathrm{o}}$ telah diperoleh 3,84 sedangkan $t_{t}=2,02$ dan 2,71 maka $t_{o}$ adalah lebih besar dari pada $t_{t}$, baik pada taraf signifikan 5\% maupun taraf signifikan $1 \%$ dengan rincian : $2,02<3,84>2,71$.

Dengan demikian Hipotesis Nihil yang menyatakan bahwa tidak terdapat perbedaan antara pemahaman konsep siswa kelas III yang menerapkan permainan engkleng dan yang tidak menerapkan permainan engkleng pada mata pelajaran matematika di SDN Bangsa Negara kabupaten OKU Timurtidak diterima atau di tolak dan Hipotesis Alternatif $\left(\mathrm{H}_{a}\right)$ diterima. 
Dedek Yunita

Pengaruh Permainan Tradisional Engkleng terhadap Pemahaman Konsep Siswa

KelaS III Mata Pelajaran Matematika di SDN Bangsa Negara Kabupaten OKU Timur

\section{Kesimpulan}

Hasil uji hipotesis dengan membandingkan besarnya $t$ yang diperoleh dalam perhitungan $\left(t_{o}=3,84\right)$ dan besarnya $t$ yang tercantum pada tabel $\left(t_{t . t s .5 \%}=2,02\right)$ dan $\left(t_{t . t s .1 \%}=2,71\right)$ maka dapat diketahui bahwa $t_{o}$ lebih besar $t_{t}$; yaitu $2,02<3,84>2,71$. Jadi, karena $t_{o}$ lebih besar dari $t_{t}$ maka hipotesis nihil yang diajukan ditolak, ini berarti bahwa adanya pengaruh permainan tradisional engkleng terhadap pemahaman konsep siswa Kelas III di SDN Bangsa Negara OKU Timur. 
Dedek Yunita

Pengaruh Permainan Tradisional Engkleng terhadap Pemahaman Konsep Siswa

KelaS III Mata Pelajaran Matematika di SDN Bangsa Negara Kabupaten OKU Timur

\section{Daftar Pustaka}

[1] D. Rahmawati dan R. Destarisa, Aku Pintar dengan Bermain, Solo: Metagraf, 2016.

[2] D. P. d. Kebudayaan, Permainan Tradisional Anak-Anak Lampung, Jakarta, 1983.

[3] A. Triharso, Permainan Kreatif \& Edukatif untuk Anak Usia Dini, Yogyakarta: Andi Offset, 2013.

[4] B. Power, Aktivitas Berbasis Minat Anak, Jakarta: Erlangga, 2005.

[5] T. Runtukahu dan S. Kandou, Pembelajaran Matematika Dasar Bagi Anak Berkesulitan Belajar, Yogyakarta: Ar-Ruzz Media, 2016.

[6] D. Rahmawati, Mengasuh Anak dengan Permainan Tradisional, Solo: Metagraf, 2016.

[7] E. Kusniati, Permainan Tradisional dan Perannya dalam Mengembangkan sosial Anak, Jakarta: PT Kharisma Putra Utama, 2016.

[8] N. I. Hasanah dan H. Pratiwi, Pengembangan anak Melalui Permainan Tradisional, Yogyakarta: Aswaja Pressindo, 2017.

[9] A. C. Perwitasari, Pengaruh Permainan Tradisional Engklek Terhadap Perkembangan Motorik Kasar Anak Usia 5-6 Tahun Di TK Bhinneka Karya Tunggulsari Dan Tk Islam Bakti Viii Wonorejo, Surakarta: 2, 2016. 